\title{
Estilos de liderazgo del director educativo
}

\section{Leadership styles of the educational director}

\author{
Kety Meza Matos \\ ketymezaf50@gmail.com \\ https://orcid.org/0000-0002-4669-1180
}

\author{
AleXandRa ShiRley Ramos Martínez \\ alesharam2@gmail.com \\ https://orcid.org/0000-0001-5031-2086
}

Universidad César Vallejo

\section{RESUMEN:}

El objetivo de este estudio es conocer la percepción acerca de los estilos de liderazgo directivo a partir de la opinión de docentes de la Unidad de Gestión Educativa Local 6 - distrito de Ate. Con tal propósito, se desarrolló una investigación con enfoque cuantitativo y basada en análisis estadístico descriptivo. Se aplico un instrumento de 56 ítems los cuales fueron respondidos a través de una escala de Likert. Los resultados del estudio muestran una percepción negativa del accionar ercido por los directores. Las conclusiones del estudio muestran que el liderazgo autoritario es el predominante, seguido de los estilos democrático y liberal.

\begin{abstract}
:
The objective of this study is to know the perception about managerial leadership styles based on the opinion of teachers from the Local 6 Educational Management Unit - Ate district. For this purpose, an investigation was developed with a quantitative approach and based on descriptive statistical analysis. An instrument of 56 items was applied which were answered through a Likert scale. The results of the study show a negative perception of the actions taken by the directors. The conclusions of the study show that authoritarian leadership is predominant, followed by democratic and liberal styles.
\end{abstract}

\section{Palabras Clave:}

Liderazgo; gestión directiva; eficacia; organizaciones públicas.

\section{KEYWORDS:}

Leadership; directive management; effectiveness; public organizations.

Recibido: 17/03/2021 - Aceptado: 5/04/2021 - Publicado: 23/06/2021

(C) Los autores. Este artículo es publicado por la Revista Peruana de Investigación e Innovación Educativa de la Facultad de Educación, Universidad Nacional Mayor de San Marcos. Este es un artículo de acceso abierto, distribuido bajo los términos de la licencia Creative Commons Atribución 4.0 Internacional (CC BY 4.0) [https://creativecommons.org/licenses/by/4.0/deed.es] que permite el uso, distribución y reproducción en cualquier medio, siempre que la obra original sea debidamente citada de su fuente original. 


\section{Introducción}

Los estilos de liderazgo son aplicados en organizaciones, en política, en los deportes, en la religión, en las guerras, entre otros. En el campo educativo, lo aplican los docentes con sus estudiantes y los directores en la gestión educativa. Esto incluye el trabajo en equipo con el personal administrativo, personal docente, y también, con el resto de integrantes de la escuela como colectivo social. Todo ello, con el fin de lograr los propósitos, metas y objetivos que son incluidos en los documentos normativos de la institución educativa.

En la actualidad, se han realizado estudios referentes al liderazgo y en las cuales, el director educativo se apoya en sus subordinados y de esta manera, se manifiesta el interés por desarrollar organizaciones eficaces con la aplicación de nuevos estilos de liderazgo para mejorar el confort de los colaboradores (Aguilera, 2011). Ello, está teniendo repercusión en los estudios realizados en América Latina y en el Perú, donde, por ejemplo, un estudio realizado por Mansilla (2007), en la Universidad Nacional Mayor de San Marcos, demuestra que el estilo y el liderazgo de los directores influye en el desempeño de su gestión en las instituciones sean estas públicas o privadas.

En la investigación anterior, el autor llega a la conclusión que el estilo del director democrático, obtiene buena aceptación con referencia a otros directores, En conclusión, los docentes calificaron que era el mejor estilo de liderazgo que puede usar el director para desarrollar las relaciones interpersonales. Este artículo está basado en el estudio a los directores de la Unidad de Gestión Educativa de Lima (UGEL) No 06 que posee instituciones educativas donde los directores buscan como inspirar y motivar a sus colaboradores para cumplir los objetivos y metas planeados, de relaciones interpersonales entre los directores, docentes, personal administrativo, y comunidad educativa.

Dentro de los trabajos previos, sobre liderazgo, que pueden considerarse en la presente investigación, se hace necesario mencionar a López (2020), cuyo objetivo fue analizar la influencia del estilo de liderazgo transformacional, donde se evalúa la influencia del carisma, la idealización inspiración que tiene el líder sobre los docentes, personal administrativo y estudiantes, aunque como aporte se agregaría, el buen trato y libertad de expresión de cada colaborador. Al respecto, el Ministerio de Educación de la República del Perú (MINEDU, 2009) indica que la autoridad suprema de una institución educativa, es el director, y adicionalmente, menciona que, posee la responsabilidad de conducir y proporcionar informe sobre los trámites que realiza. Asimismo, que es la persona que resuelve los conflictos que surge en el centro educativo; su liderazgo se fortalece los valores éticos, morales y democráticos que el país demanda.

Se ha considerado como bases teóricas, el liderazgo y los estilos de liderazgo, en la cual se sustenta la investigación. Para empezar, se define que es liderazgo y se toma en consideración a Fiedler (1984), que refiere al liderazgo como la forma de motivar en otros, para que se genere entusiasmo para cumplir sus objetivos. En tal sentido, se infiere que el acto de liderar implica una movilización de esfuerzos humanos para consolidar los objetivos personales y estratégicos. El autor señala que, el liderazgo nos da la capacidad de persuadir, influir sobre los seguidores, pero para influir en ellos se tiene que motivarlos y hacer que tengan la percepción de ser un modelo a seguir sino se consigue lograr lo definido y solo se cumplirá a través de una comunicación fluida y constante.

Asimismo el autor Chiavenato (2006) refiere que, el liderazgo es la manera de influir sobre sus seguidores, que sin una buena comunicación eficaz y constante no se puede lograr un buen liderazgo. Entre las teorías que sustentan los estilos de liderazgo se resalta las dimensiones de los estilos de liderazgo y donde se ha seleccionado, de todos los estilos de liderazgo, solo tres tipos de liderazgo importantes, como son: el del líder autoritario. Según Maureira (2018) precisa que es aquel jefe, supervisor, director o cualquier trabajador que este al mando de un grupo humano, donde el impone lo que se tiene que hacer o como deben de actuar los colaboradores, sin considerar las sugerencias de ellos y ni la opinión de otros más que su voluntad. 
En cambio, el líder democrático, Duran-Seguel, Gallegos y Cabezas (2019), permite a todos sus colaboradores dar sus opiniones, colaboren y participen en el análisis de resolución de los problemas y trabajen de manera colaborativa y participativa para lograr los fines y propósitos institucionales.

En el caso del líder liberal, Maureira (2018) refiere que los trabajadores tienen amplia libertad para la toma de decisiones según las normas o funciones a cumplir dentro de la organización, hay confianza por parte del líder sobre sus subordinados o colaboradores y esto conforta a muchos trabajadores, porque el objetivo es lograr resultados; esto también se puede aplicar en la educación, porque el director no lo puede ver todo ni resolver todo el solo sino con el apoyo y aporte de sus colaboradores.

\section{Método}

El método utilizado en la investigación científica es hipotético deductivo, porque se observó a los agentes de estudio y se proyectó hipótesis sobre los mismos. Asimismo, el enfoque es cuantitativo de corte transversal, el diseño es no experimental debido a que "las variables no tienen manipulación, los grupos de estudio son libres" (Carrasco, 2009, p. 71). Adicionalmente, es de subtipo correlacional; la técnica que se aplicó a la investigación es la encuesta y el instrumento es el cuestionario que fue aplicado a los docentes de la UGEL 06.

En cuanto a la población estudiada, esta estuvo conformada por p0s docentes de la UGEL 06 de Ate Vitarte, Lima, Perú; mientras que la muestra incluyó a 120 docentes de ocho instituciones educativas públicas de educación básica regular. El tipo de muestreo fue no probabilístico por conveniencia. En cuanto a los resultados obtenidos son de carácter cuantitativo.

\section{Resultados}

Interpretación: De la tabla 1, se observa que el 94\% (113) de los docentes afirman que el estilo de liderazgo es autoritario, según los datos recogidos.

Tabla 1

Resultados respecto al estilo de liderazgo predominante

\begin{tabular}{lcc}
\hline Liderazgo & Frecuencia & Porcentaje \\
\hline Autoritario & 113 & $94 \%$ \\
Democrático & 4 & $3 \%$ \\
Liberal & 4 & $3 \%$ \\
Total & 120 & $100 \%$ \\
\hline
\end{tabular}

Nota: Cuestionarios aplicados.

Interpretación: De la tabla 2, se observa que el 46\% (55) de los docentes consideran que el estilo de liderazgo autoritario es alto según los datos recogidos.

Tabla 2

El liderazgo directivo autoritario

\begin{tabular}{lcc}
\hline Nivel & Frecuencia & Porcentaje \\
\hline Baja & 23 & $19 \%$ \\
Moderada & 42 & $35 \%$ \\
Alta & 55 & $46 \%$ \\
Total & 120 & $100 \%$ \\
\hline
\end{tabular}

Nota: Cuestionarios aplicados a los docentes.

Interpretación: De la tabla 3, se observa que el 75\% (91) de los docentes consideran que el estilo de liderazgo democrático es bajo. 
Tabla 3

El liderazgo directivo democrático según docentes de las Instituciones Educativas de la Red 6, UGEL 06 de Ate - Vitarte 2014.

\begin{tabular}{lcc}
\hline Nivel & Frecuencia & Porcentaje \\
\hline Baja & 91 & $75 \%$ \\
Moderada & 16 & $14 \%$ \\
Alta & 13 & $11 \%$ \\
Total & 120 & $100 \%$ \\
\hline
\end{tabular}

Nota: Cuestionarios aplicados a los docentes.

Interpretación: De la tabla 4, se observa que el 69\% (83) de los docentes consideran que el liderazgo directivo es liberal.

Tabla 4

El liderazgo directivo liberal según docentes de las Instituciones Educativas de la Red 6, UGEL 06 de Ate - Vitarte 2014.

\begin{tabular}{lcc}
\hline Nivel & Frecuencia & Porcentaje \\
\hline Baja & 26 & $22 \%$ \\
Moderada & 83 & $69 \%$ \\
Alta & 11 & $9 \%$ \\
Total & 120 & $100 \%$ \\
\hline
\end{tabular}

Nota: Cuestionarios aplicados a los docentes.

\section{Discusión}

Con base en los resultados, se infiere que la mayoría de los docentes (94\%) percibe que el liderazgo de sus directores es autoritario, frente a un 3\% de autoritario democrático y liberal. Por otro lado, los docentes encuestados perciben el liderazgo directivo autoritario en un nivel alto (46\%), moderado en un $35 \%$ y bajo en $19 \%$. En cuanto al estilo democrático, los resultados muestran que la percepción alcanza un nivel bajo (75\%), moderado $(14 \%)$ y alto (11\%).

Asimismo, respecto al estilo liberal, los resultados ubican a este estilo, en un nivel moderado (69\%), bajo (22\%) y alto (9\%). Estos hallazgos confirman la postura teórica de Duran-Seguel, Gallegos y Cabezas (2019) quienes sostienen, la trascendencia del líder al interior de las instituciones y que en un contexto democrático, los servidores pueden tener la capacidad de tomar decisiones más a título personal lo que podría provocar la integración y la participación más abierta de las personas, todo ello sin contravenir las disposiciones normativas de la institución.

\section{Conclusiones}

Como conclusiones se puede afirmar que en las instituciones participantes en este estudio existen tres estilos de liderazgo: el autoritario, el democrático y el liberal. La mayor percepción por parte de los docentes encuestados asume que el liderazgo autoritario es el predominante. En tal sentido, se infiere que las relaciones laborales podrían estar encaminadas a concretar los objetivos de la institución, pero la mirada que se tiene de los directivos, por parte del cuerpo docente es que, se actúa de manera impositiva, con falta de dialogo abierto y sin dar la oportunidad a que se acepten opiniones.

Adicionalmente, este ambiente puede o podría tener más adelante consecuencias negativas para la escuela (rivalidad entre docentes - directivos, entre docentes, resistencia a la reglamentación emanada de las autoridades, entre otros). Es propicia la oportunidad para reflexionar acerca de esta situación debido a que la 
escuela se le conoce como una comunidad educativa, un colectivo social que no solamente basa su accionar en reglas, normas y procedimientos sino también en relaciones sociales cordiales.

\section{Referencias}

Aguilera, V. (2011). Liderazgo y clima de trabajo en las instituciones educativas de la Fundación Creando Futuro. España: Universidad de Alcalá

Carrasco, S. (2009). Metodología de la investigación cientifica. Lima: San Marcos.

Chiavenato, I. (2006). Introducción a la Teoría General de la Administración, (7ª ed.). Mc Graw Hill.

Duran-Seguel, I., Gallegos, M., y Cabezas, D. (2019). Estilos de liderazgo y su influencia en el clima laboral: caso de estudio de una empresa exportadora de alimentos. Revista Espacios, 40(40), 3-16. http://www.revistaespacios. com/a19v40n40/a19v40n40p03.pdf

Fiedler, F. (1984). Teoría de contingencia del liderazgo. McGraw Hill.

López, C. (2020). Liderazgo transformacional y gestión administrativa en los

trabajadores de la Dirección Regional de Agricultura de Tumbes, 2020, (Tesis de maestría, Universidad César Vallejo). https://repositorio.ucv.edu.pe/bitstream/handle/20.500.12692/51516/L\%C3\%B3pez_FCJ\%20-\%20SD. pdf?sequence $=1 \&$ isAllowed $=y$

Mansilla, J. (2007). Influencia del estilo de liderazgo y la gestión eficaz de tres directores en el rendimiento académico de los estudiantes, en la Cohorte Educativa 2001- 2005 de la Institución Inmaculada Concepción - Lima (Tesis de maestría, Universidad Nacional Mayor de San Marcos). https://cybertesis.unmsm.edu.pe/bitstream/ handle/20.500.12672/2373/Mansilla_gj.pdf?sequence=1

Maureira, Ó. (2018). Prácticas del liderazgo educativo: Una mirada evolutiva e ilustrativa a partir de sus principales marcos, dimensiones e indicadores más representativos. Revista Educación, 42(1),1-33. https://www.redalyc.org/ articulo.oa?id $=44051918001$

MINEDU. (2009). Aprendiendo a resolver conflictos en las instituciones educativas. Tutoría y orientación educativa. Perú: Quebecor Word Perú, SA.

\section{Como citar este artículo:}

Meza, K. y Ramos, A. (2021). Estilos de liderazgo del director educativo. Revista Peruana de Investigación e Innovación Educativa, 1 (1), 80-90 
